\title{
Prevalence of gestational diabetes mellitus and associated factors among women attending antenatal care at Gondar town public health facilities, Northwest Ethiopia
}

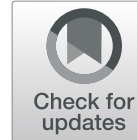

Achenef Asmamaw Muche ${ }^{1,2^{*}}$, Oladapo O. Olayemi ${ }^{3}$ and Yigzaw Kebede Gete ${ }^{2}$

\begin{abstract}
Background: Globally, Gestational Diabetes Mellitus (GDM) is rising, but it is a neglected health threat to mothers and their children in low resource countries. Although, GDM is known in Ethiopia, information regarding it remains scarce by recent diagnostic criteria. Therefore, this study aimed to determine the prevalence of GDM and associated factors among women attending antenatal care at Gondar town public health facilities, Northwest Ethiopia.

Methods: A cross-sectional study was conducted among 1027 pregnant women selected by the systematic random sampling technique. The universal one-step screening and diagnostic strategy was done using a two-hour $75 \mathrm{~g}$ oral glucose tolerance test. GDM was diagnosed using updated diagnostic criteria (2017 American Diabetes Association (ADA) or 2013 World Health Organization (WHO) or modified International Association of the Diabetes and Pregnancy Study Groups diagnostic criteria (IADPSG)). Binary logistic regression model was used to identify factors associated with GDM.

Results: Of the total 1027 pregnant women, $12.8 \%$ (95\% Cl: 10.8-14.8) were diagnosed with GDM. Overweight and/or obesity ( $M U A C \geq 28 \mathrm{~cm})(\mathrm{AOR}=2.25,95 \% \mathrm{Cl}: 1.18-4.26)$, previous history of $\mathrm{GDM}(\mathrm{AOR}=5.82,95 \% \mathrm{Cl}: 2.57-13.18)$, family history of diabetes ( $A O R=4.03,95 \% \mathrm{Cl}: 1.57-10.35)$, low physical activity $(A O R=3.36,95 \% \mathrm{Cl}: 1.60-7.04)$, inadequate dietary diversity $(A O R=1.9,95 \% \mathrm{Cl}: 1.02-3.53$ ), and antenatal depression ( $\mathrm{OOR}=4.12,95 \% \mathrm{Cl}: 1.85-9.20$ ) were significantly associated with GDM.

Conclusions: The prevalence of GDM among women attending antenatal care at Gondar town public health facilities was high. Previous history of GDM, antenatal depression, family history of diabetes, low physical activity, overweight and/ or obesity and inadequate dietary diversity were significantly associated with GDM. Routine screening of pregnant women and healthy lifestyle are strongly recommended.
\end{abstract}

Keywords: Gestational diabetes mellitus, Determinants, Overweight, Obesity, Physical activity, Dietary diversity, Antenatal depression

\footnotetext{
* Correspondence: ashua2014@gmail.com

${ }^{1}$ Pan African University Life and Earth Sciences Institute (including health and

agriculture), Department of Obstetrics and Gynaecology, College of

Medicine, University of Ibadan, Ibadan, Nigeria

${ }^{2}$ Department of Epidemiology and Biostatistics, Institute of Public Health,

University of Gondar, Gondar, Ethiopia

Full list of author information is available at the end of the article
}

(c) The Author(s). 2019 Open Access This article is distributed under the terms of the Creative Commons Attribution 4.0 International License (http://creativecommons.org/licenses/by/4.0/), which permits unrestricted use, distribution, and reproduction in any medium, provided you give appropriate credit to the original author(s) and the source, provide a link to the Creative Commons license, and indicate if changes were made. The Creative Commons Public Domain Dedication waiver (http://creativecommons.org/publicdomain/zero/1.0/) applies to the data made available in this article, unless otherwise stated. 


\section{Background}

The World Health Organization (WHO) defined "Gestational Diabetes Mellitus (GDM) as glucose intolerance first detected during pregnancy" [1]. Various adverse maternal and neonatal outcomes were complicated by GDM [2], while its complex care requires risk reduction strategies beyond the control of blood glucose level [3].

Globally, GDM affects an estimated 15\% of the pregnant women, $87.6 \%$ of the hyperglycemia were in low and middle-income countries. It is one of the challenging health problems of sub-Saharan African countries [4].

A review indicated that the occurrence of GDM in sub-Saharan Africa was 14\% [5] and Middle East and North Africa ranged from 8.4 to 24.5\% [6] though the study used different screening and diagnostic criteria. Research findings also showed that the prevalence of GDM varied to a certain extent among regions in Africa. For example, East [7] and West [8] Africa reported 6 and $14 \%$, respectively. Variations were also noted within sub-regions, like Rwanda [9] and Tanzania [10], where the prevalence was 8.3 and $19.5 \%$, respectively. Two decades ago, the prevalence of GDM in the rural area of North Ethiopia was reported as 3.7\% [11]. Additionally, a survey done in the same region (North Ethiopia) found a prevalence of $13 \%$ among urban women which was higher than that of women in rural areas (5\%) [12]. However, the study used only fasting blood glucose test as diagnostic criteria for GDM.

According several studies, the increasing occurrence of GDM was related to advanced age, family history of diabetes, inactive physical activity, obesity, and risky behaviors [13-15]. Studies had also recognized that there was association between dietary habits during pregnancy and GDM. However, there had been no concrete consensus on the effects specific dietary aspects and the risk for GDM [16-18].

Gestational diabetes mellitus commonly identified during the second or third trimester of pregnancy as a result of the placental hormone plays an important role in the adverse effect on glucose metabolism [2]. As pregnancy progresses, various hormones such as estrogen, progesterone, leptin, cortisol, placental lactogen, and placental growth hormone promote a state of insulin resistance [19]. Primarily, human placental lactogen produced by placenta raises maternal blood glucose level and makes a woman's body less sensitive to insulin leading to a higher-than-normal blood glucose level and perhaps GDM [20].

After the pre-existing diabetes (overt diabetes) is ruled out at the first antenatal visit, the recommended oral glucose tolerance test (OGTT) has to be performed at 24-28 weeks of pregnancy [21, 22]. However, since there has been no well-established national guideline for GDM screening in the country, most clinicians focus on risk factors to indicate GDM screening. This approach was leaving many pregnant women unnoticed until they develop symptoms of overt diabetes and complications.

Recognizing GDM offers an opportunity to reduce adverse pregnancy outcomes and improve the lifestyle to prevent the occurrence of diabetes in the future [23, 24]. Moreover, as per the knowledge of the principal investigator, no study has been conducted on prevalence of GDM in Ethiopia using the updated international diagnostic criteria. Therefore, the present study aimed to determine the prevalence of GDM and associated factors among women attending antenatal care at selected Gondar town public health facilities, Northwest Ethiopia.

\section{Materials and methods \\ Study setting}

The study was conducted at selected Gondar town public health facilities. It included one tertiary facility called University of Gondar Comprehensive Specialized Hospital (UOGCSH) and four health centers namely, Azezo, Gondar polyclinic, Woleka, and Maraki. Gondar town is located in the Northwestern part of Ethiopia, $747 \mathrm{~km}$ from Addis Ababa (the capital of Ethiopia), and $170 \mathrm{~km}$ from Bahirdar (the regional capital). It has 12 sub-cities with 12 urban and 10 rural kebeles (the smallest administrative units). Based on the 2014 population projection and census of the Central Statistical Agency (CSA) of Ethiopia [25], the total population of the town was estimated to be 306, 246 of whom 149, 970 were men and 156, 276 women. The majority (84.2\%) of the people were Orthodox Christians, 11.8\% Muslims and 1.1\% Protestants. The expected number of pregnant women in the town was 11,225 , of which at least 8913 were living in urban kebeles in 2017/18. The town had one comprehensive specialized hospital, eight health centers, and more than 15 private clinics.

\section{Study design, sample size, and sampling procedure}

A cross-sectional study was conducted among a cohort of pregnant women receiving antenatal care at selected public health facilities from March 30, 2018 to January 4,2019 . The required sample size was determined using the single population proportion formula with the following statistical assumptions: a survey conducted by Management Sciences for Health (MSF) reported the prevalence of GDM among urban women in Tigray, Northern Ethiopia as 13\% [12], a 95\% confidence level, $3 \%$ marginal of error, a design effect of 2 , and considering $15 \%$ of non-response and attrition rates. 


\section{Applying the formula}

$$
\begin{aligned}
\mathrm{n} & =\frac{(\mathrm{z})^{2} \mathrm{P}(1-\mathrm{P})}{\mathrm{d}^{2}} \quad n=\frac{(1.96)^{2} .13(1-.13)}{(0.03)^{2}}=482.7 \quad \mathrm{n} \\
& =482.7 \mathrm{x} 2 \quad \text { (design effect) }=965
\end{aligned}
$$

Where, $\mathrm{n}=$ the sample size, $\mathrm{Z}=$ the desired level of the confidence interval, $\mathrm{P}=$ proportion of GDM, and $\mathrm{d}=$ margin of error. The minimum required sample size for significant result was 965 , however we have added $15 \%$ by considered the non-response and attrition rates throughout the study period.

Therefore a total of 1110 were recruited for the study. A two-stage sampling technique used to invite pregnant mothers and include them in the cohort. On the first stage, one hospital and four health centers were selected by the simple random sample; on the second stage, pregnant women who fulfilled the inclusion criteria were chosen using the systematic random sampling technique.

\section{Participant selection and recruitment}

During the study, 1110 new antenatal care attendants were invited and screened to participate in the study. Women were enrolled if they were aged 18 years or more with $20-23^{+6}$ weeks of gestational age and singleton pregnancy. But pregnant women who had pre-existing diabetes mellitus or overt DM, chronic diseases, medications that may affect glucose metabolism such as steroids, $\beta$-adrenergic agonists, anti-psychotic drugs $[26$, 27] were excluded. On their first visit, participants were asked for written consent for their enrolment in the study.

Screening at first visit was carried out according to the recommendations of the International Diabetes Federation (IDF) [22], ADA [28], and WHO [29] in order to rule out pre-existing diabetes. However, most pregnant women did not fast in their first visits. For subsequent tests, participants were informed to come fasting on their next appointments. Universal screening for GDM using a two-hour $75 \mathrm{~g}$ OGTT was performed for all pregnant women at 24-28 weeks of gestational age. Besides, 352(34.3\%) women had at least one type of risk factors for GDM (pre pregnancy $B M I \geq 30 \mathrm{Kg} / \mathrm{m}^{2}$, MUAC $\geq 28 \mathrm{~cm}$, age $\geq 35$ years, previous macrosomia, glycosuria, history of GDM, family history of diabetes, previous poor pregnancy outcome or developed pregnancy-related complications) were advised to repeat the test at 32-36 weeks even if their OGTT results were negative at regular tests and GDM diagnosis ascertained by the second test.

\section{Data collection}

\section{Demographic, obstetric, lifestyle, and anthropometric information}

A structured and pretested questionnaire was developed and interviewer-administered to all study participants The questionnaire was prepared in English and then translated to Amharic (the local and national language) and then translated back to English by language experts to check its consistency (English version questionnaire attached as Additional file 1).

A face to face interview was employed to gather information on residence, age, last normal menstrual period (LNMP), marital status, religion, ethnicity, level of education, occupational status, average monthly income, family history of diabetes, previous history of GDM and birth weight of the previous child, behavioral and lifestyle characteristics, such as current exposure to alcohol, coffee, antenatal depressive symptoms, physical activity, and dietary diversity. Gestational age estimations were based on a reliable LNMP combined with first-trimester ultrasonography (if available). Additionally, socio-demographic information (parity, gravidity, gestational age (early fetal ultrasound result), obstetric history, medical history, hemoglobin) were retrieved from ANC cards.

The short form International Physical Activity Questionnaire (IPAQ) was used to assessed the physical activities that women do as part of their everyday lives [30]. The IPAQ was suitable for adults between 15 and 69 years of age and implemented in different countries. It was designed to assess specific types of activity such as walking, moderate and vigorous intensity activities done at work, as part of house and yard work, to get place to place, and in spare time for recreation, exercise or sport. Women were asked to recall their activities of the last 7 days preceding the interview. Data was reported as metabolic equivalents (MET-minutes per week) using the IPAQ scoring protocol to considered women into high, moderate and low level of physical activity categories [30].

Dietary diversity was assessed using a 24-h food recall method by the Food and Nutrition Technical Assistance (FANTA) 2016 version woman's minimum dietary diversity measurement tool [31]. It contained a list of ten food groups (starchy staples, nuts and seeds, pulses, dairy, meat, eggs, poultry and fish, dark green leafy vegetables, other vitamin-A rich fruits and vegetables, other vegetables, and other fruits). The minimum dietary diversity score (MDDS) was dichotomized on the basis of whether or not women have consumed the list of defined food groups the previous day or night. The MDDS of five and more was categorized as adequate dietary diversity [31].

A mother was asked, "How often have you drunk coffee since your pregnancy?" If the answer was "daily" or 
"sometimes in a week" the mother was categorized as exposed to coffee. She was also asked, "How often have you drunk alcohol since your pregnancy?" If the answer was "daily" or "sometimes in a week" the mother was labelled as exposed to alcohol.

The mid-upper arm circumference (MUAC) was measured on the left arm using a non-stretchable measuring tape. As the result of most of the pregnant women could not recall their weight before conception, it was difficult to determine BMI. MUAC was as reliable measure due to quite stable during the course of pregnancy and highly correlated to the BMI before conception [32, 33]. Pregnant women with MUAC of $\geq 28 \mathrm{~cm}$ were considered as having overweight and/or obesity [34].

For measuring blood pressure (BP), the pregnant women were asked to take rest for at least $5 \mathrm{~min}$ in sitting positions if they were exerted. Then, the pressure was measured on the right arm using normal cuffs fitted for adults with a standard sphygmomanometer placing the stethoscope bell lightly over the brachial artery. The average systolic blood pressure (SBP) and diastolic blood pressure (DBP) were recorded in $\mathrm{mmHg}$ after two readings were taken with an intermission of 5-10 min. Hypertension was considered to be present if the systolic and diastolic blood pressures were greater than or equal to $140 \mathrm{mmHg}$ and $90 \mathrm{mmHg}$, respectively.

Antenatal depression symptoms were measured by using the Edinburgh Postnatal Depression Scale (EPDS) screening tool developed [35] and validated in urban Ethiopia [36]. The tool was used to measure the feelings a mother had experienced in the past week. The tool contains ten specific questions with four Likert scale response options (most of the time, sometimes, not often, never), scored from 0 to 3 (a higher score indicated more depressive symptoms), which is simple to use, can be scored by simple addition. An EPDS score of 13 and more used like similar studies conducted in Ethiopia and abroad [37-39] to categorize the presence of antenatal depression.

\section{Laboratory assessment}

Pregnant women scheduled for $2 \mathrm{~h}-75 \mathrm{~g}$ OGTT were called and reminded to complete an overnight fast for 8-12 h. Blood glucose level was analyzed using $5 \mu \mathrm{l}$ capillary whole blood with HemoCue Glucose B-201 ${ }^{+}$ (A"ngelholm $A B$, Sweden). (The specifications of the HemoCue Glucose B-201 ${ }^{+}$glucometer attached as Additional file 2). Pregnant women were asked to sit and take rest before the first sample was taken using a finger prick at the side of the fingertip with a sterile lancet after cleaning in disinfectant and allowed to dry. A drop of blood was allowed to fill the cuvette after wiping away the first 2 or 3 drops of blood. Wipe off excess blood on the outside of the cuvette tip and place the filled cuvette in the cuvette holder. After 40-240 s the glucose value of the sample was displayed. The necessary precautions were taken during sample collection. Then, they were given a $75 \mathrm{~g}$ of glucose dissolved in $250 \mathrm{~mL}$ of water which they drank within $5 \mathrm{~min}$ under supervision. Capillary blood samples were taken again at $1 \mathrm{~h}$ and $2 \mathrm{~h}$. The whole blood capillary values were converted to plasma venous values by multiplying a constant factor of 1.11 [40]. GDM diagnosis was made by using the 2017 American Diabetes Association (ADA) [28] or $2013 \mathrm{WHO}$ [41] or modified International Association of the Diabetes and Pregnancy Study Groups (IADPSG) [42] diagnostic criteria. Similar values have been accepted by the WHO though slightly modified as a range [29]. The diagnosis of GDM is made when one or more of the values was met (fasting: $\geq 92$ $\mathrm{mg} / \mathrm{dL}, 1 \mathrm{~h}: \geq 180 \mathrm{mg} / \mathrm{dL} ; 2 \mathrm{~h}: \geq 153 \mathrm{mg} / \mathrm{dL}$ ). Hemoglobin analysis was also carried out by laboratory technologists in their respective health facilities. Pregnant women with hemoglobin concentration below $11 \mathrm{~g} / \mathrm{dl}$ were considered as having anaemia [43].

\section{Statistical analysis}

All data were entered into Epi Info ${ }^{\text {tm }} 7$ software, then exported to statistical package for the social sciences (SPSS) version 22.0 (IBM, NY, USA) for analysis. Descriptive statistics, like frequency, percentage, and mean, $\mathrm{SD}$, and the range were used for the presentation of variables. Tables and figure were also used for data presentation. Categorical variables were expressed as proportions and chi-square analysis was performed to compare proportions. Student t-test was used to compare means for normally distributed variables. Binary logistic regression model was used to identify factors associated with GDM. Variables with $P$-value of $\leq 0.20$ in the bivariate analysis were exported to the multivariate analysis to control the possible effect of confounders. Model goodness of fit test was checked by the Hosmerand Lemeshow test $(P$-value $=0.953)$. Multicollinearity was checked by using the variance inflation factor (VIF). Adjusted Odds Ratio (AOR) with a 95\% confidence level was estimated to show the strength of association, and a $P$-Value $<0.05$ was used to declare statistical significance in the multivariate analysis.

\section{Results \\ Socio demographic and clinical characteristics of pregnant mothers}

Out of the 1110 pregnant women invited to participate in the study, 83 mothers (52 did not return for OGTT, 15 did not complete the tests, 9 were diagnosed with overt diabetes, 5 have a medical emergency, and 2 had an abortion before OGTT) were excluded. The characteristics of pregnant women who of included and excluded in the final analysis were similar in terms of 
key socio demographic variables such as residence $(P=$ $0.835)$, maternal age $(P=0.0691)$, parity $(P=0.544)$, gravidity $(P=0.109)$, marital status $(P=0.734)$, MUAC $(P=$ $0.08)$, employment status $(P=0.056)$. However women with complete data were on average attended secondary educational level and above and had higher income level than those who were excluded in the analysis.

The remaining 1027 women who participated and completed OGTT with overall response rate of $92.5 \%$ were included in the analysis. The mean age of the women was $27.22(\mathrm{SD} \pm 5.24)$ years. Most of the participants (91\%) lived in urban areas, 92\% were married, and $60.5 \%$ unemployed. Five hundred and ninety-eight (58.2\%) of women had secondary education and above. The mean of the MUAC was $24.77(\mathrm{SD} \pm 3.08) \mathrm{cm}$, systolic blood pressure was $112.07(\mathrm{SD} \pm 11.91) \mathrm{mmHg}$, and diastolic blood pressure was $71.91(\mathrm{SD} \pm 10.22) \mathrm{mmHg}$. The mean hemoglobin level of the pregnant women with GDM and normal glucose level was 12.39 (SD \pm 1.80$) \mathrm{g} /$ $\mathrm{dl}$ and $12.64(\mathrm{SD} \pm 1.74) \mathrm{g} / \mathrm{dl}$, respectively. Nearly half, $504(49.1 \%)$ of the women were nulliparous. Sixty-two (6\%) had a family history of DM (Table 1).

\section{Behavioral and lifestyle characteristics of pregnant mothers}

Out of total participants, a moderate level of physical activity was reported by $44.8 \%$. Normal glucose level was more common among women having high physical activity level (33.4\% vs $17.6 \%)$ and adequate dietary diversity (51.5\% vs $27.5 \%$ ) than women with GDM. Concerning exposure to drinking alcohol and coffee, no statistically significant difference was observed among women with normal glucose profile and GDM at $P=$ 0.476 and $P=0.311$ respectively. Eighty-nine $(8.7 \%)$ of the pregnant women had antenatal depression symptoms (Table 2).

\section{Obstetric history of pregnant mothers}

Of the total of 588 pregnant women who had prior pregnancy history, 71(12.1\%) had macrocosmic babies, 166 (28.2\%) history of abortion, 38 (6.5\%) history of stillbirth, 42 (7.1\%) history of preterm labor, $97(16.5 \%)$ history of caesarean delivery, and $54(9.2 \%)$ previous GDM (Table 3).

\section{Prevalence of GDM}

A total of 131 women were diagnosed as having GDM according to 2017 ADA and IADPSG diagnostic criteria which resulted in a GDM prevalence of $12.8 \%$ (95\% CI: $10.7-14.8 \%) ; 118$ (90\%) of them were diagnosed at regular OGTT and the rest $13(10 \%)$ at late OGTT. At regular OGTT test (24-28 weeks), the mean fasting, $1 \mathrm{~h}$, and 2-h glucose levels of the pregnant women were $81.17(\mathrm{SD} \pm 12.96) \mathrm{mg} / \mathrm{dl}, 140.69(\mathrm{SD} \pm 24.55) \mathrm{mg} / \mathrm{dl}$, and
$119.10(\mathrm{SD} \pm 19.75) \mathrm{mg} / \mathrm{dl}$, respectively. The plasma glucose levels taken at the three time points of the OGTT were significantly different for women with GDM and normal glucose level $(p<0.001)$. Pregnant women with GDM had the mean fasting, one-hour and two-hour glucose level of $100.81(\mathrm{SD} \pm 15.88) \mathrm{mg} / \mathrm{dl}, 163.82(\mathrm{SD} \pm$ $28.42) \mathrm{mg} / \mathrm{dl}$, and $138.76(\mathrm{SD} \pm 23.40) \mathrm{mg} / \mathrm{dl}$, respectively. Whereas, women with normal glucose profiles had the mean fasting, one-hour and two-hour glucose levels of $78.3(\mathrm{SD} \pm 9.55) \mathrm{mg} / \mathrm{dl}, 137.31(\mathrm{SD} \pm 22) \mathrm{mg} / \mathrm{dl}$, and $116.22(\mathrm{SD} \pm 17.4) \mathrm{mg} / \mathrm{dl}$, respectively (Table 1$)$. More than half $(56.5 \%)$ of the women with GDM were diagnosed on a fasting plasma glucose status only, while $21.4 \%$ had high fasting glucose level and one or two extra abnormal levels (Fig. 1).

\section{Factors associated with GDM}

Results of the unadjusted binary logistic regression showed that advanced maternal age, marital status, level of education, employment status, MUAC $\geq 28 \mathrm{~cm}$, parity, previous history of GDM, family history of DM, history of having macrocosmic baby, history of abortion, history of stillbirth, SBP, DBP, anemia $(\mathrm{Hb}<11 \mathrm{~g} / \mathrm{dl})$, level of physical activity, dietary diversity, and antenatal depression were associated with GDM. However, on multivariate logistic regression, variables GDM was independently associated with being overweight and/or obese women $($ MUAC $\geq 28 \mathrm{~cm})$ AOR $=2.25$; 95\% CI: 1.18-4.26), previous history of GDM (AOR $=5.82$; 95\% CI: 2.57-13.18), family history of diabetes (AOR $=4.03$; $95 \% \mathrm{CI}$ : $1.57-$ 10.35 ), low physical activity ( $\mathrm{AOR}=3.36$; $95 \% \mathrm{CI}: 1.60$ 7.04), inadequate dietary diversity $(\mathrm{AOR}=1.9 ; 95 \% \mathrm{CI}$ : $1.02-3.53)$, and antenatal depression ( $\mathrm{AOR}=4.12$; $95 \%$ CI: 1.85-9.20) were significantly associated with GDM (Table 4).

\section{Discussion}

This study was conducted to determine the prevalence of GDM and associated factors among women attending antenatal care at Gondar town public health facilities, Northwest Ethiopia, using the updated international diagnostic criteria.

In this study, the overall prevalence of GDM among women was $12.8 \%$ (95\% CI: 10.8-14.8). The result was consistent with the Management Sciences for Health (MSF) reported the prevalence of GDM among urban women in Tigray, Northern Ethiopia (13\%), but the study used only a fasting blood glucose test which means it did not consider internationally recommended diagnostic criteria [12]. The finding was higher than those of studies conducted in Rwanda (8.3\%) [9], Tanzania (5.9\%) [7], Egypt (8\%) [44], and Nigeria (8.6\%) [45]. The main reason for the high prevalence of GDM in this study setting might be the fact that the lower cut-off points for 
Table 1 Socio demographic and clinical characteristics of the study participants attending antenatal care at Gondar town public health facilities, Northwest Ethiopia: March 2018-January $2019(N=1027)$

\begin{tabular}{|c|c|c|c|c|c|}
\hline \multirow[t]{2}{*}{ Variables } & \multicolumn{3}{|l|}{$\underline{\mathrm{n}(\%) \text { or mean } \pm \mathrm{SD}}$} & \multirow[t]{2}{*}{$t / x^{2}$} & \multirow[t]{2}{*}{$P$ value } \\
\hline & Total participants $(n=1027)$ & Normal $(n=896)$ & $\operatorname{GDM}(n=131)$ & & \\
\hline Maternal age (years) & $27.22 \pm 5.241$ & $26.69 \pm 5.047$ & $30.86 \pm 5.109$ & 8.827 & $<0.001$ \\
\hline$<25$ & $323(31.5)$ & $304(94.1)$ & $19(5.9)$ & 61.108 & $<0.001$ \\
\hline $25-29$ & $366(35.6)$ & $335(91.5)$ & $31(8.5)$ & & \\
\hline $30-34$ & $214(20.8)$ & $168(78.5)$ & $46(21.5)$ & & \\
\hline$\geq 35$ & $124(12.1)$ & $89(71.8)$ & $35(28.2)$ & & \\
\hline \multicolumn{6}{|l|}{ Marital status } \\
\hline Married & $945(92)$ & $831(87.9)$ & $114(12.1)$ & 5.094 & 0.024 \\
\hline Single and others ${ }^{a}$ & $82(8.0)$ & $65(79.3)$ & $17(20.7)$ & & \\
\hline \multicolumn{6}{|l|}{ Educational level } \\
\hline Not formal education & $200(19.5)$ & $168(84)$ & $32(16.0))$ & 5.472 & 0.065 \\
\hline Primary education & $229(22.3)$ & $194(84.7)$ & $35(15.3)$ & & \\
\hline Secondary education and above & $598(58.2)$ & $534(89.3)$ & $64(10.7)$ & & \\
\hline \multicolumn{6}{|l|}{ Employment status } \\
\hline Unemployed & $621(60.5)$ & $556(89.5)$ & $65(10.5)$ & 7.393 & 0.007 \\
\hline Employed & $406(39.5)$ & $340(83.7)$ & $66(16.3)$ & & \\
\hline \multicolumn{6}{|l|}{ Residence } \\
\hline Urban & $935(91)$ & $812(86.8)$ & $123(13.2)$ & 1.497 & 0.221 \\
\hline Rural & $92(9.0)$ & $84(91.3)$ & $8(8.7)$ & & \\
\hline Monthly income (birr) & $3159.7 \pm 2973.05$ & $3155.17 \pm 2952.66$ & $3190.8 \pm 3120.55$ & 0.128 & 0.898 \\
\hline$<1500$ & $236(23)$ & $203(86)$ & $33(14)$ & 1.641 & 0.650 \\
\hline $1500-2499$ & $257(25)$ & $230(89.5)$ & $27(10.5)$ & & \\
\hline 2500-3999 & $230(22.4)$ & 199 (86.5) & $31(13.5)$ & & \\
\hline$\geq 4000$ & 304 (29.6) & 264(86.8) & $40(13.2)$ & & \\
\hline \multicolumn{6}{|l|}{ Family history of DM } \\
\hline No & $965(94)$ & $862(89.3)$ & $103(10.7)$ & 62.264 & $<0.001$ \\
\hline Yes & $62(6)$ & $34(54.8)$ & $28(45.2)$ & & \\
\hline Parity & $0.92 \pm 1.208$ & $0.91 \pm 1.227$ & $1.02 \pm 1.063$ & 1.013 & 0.311 \\
\hline Nullipara & $504(49.1)$ & 449 (89.1) & $55(10.9)$ & 5.717 & 0.057 \\
\hline Primipara & $277(27)$ & $243(87.7)$ & $34(12.3)$ & & \\
\hline Multipara & $246(24)$ & $204(82.9)$ & $42(17.1)$ & & \\
\hline Gravidity & $2.12 \pm 1.354$ & $2.09 \pm 1.364$ & $2.32 \pm 1.267$ & 1.838 & 0.066 \\
\hline Primigravida & $439(42.7)$ & $395(90)$ & $44(10)$ & 5.146 & 0.023 \\
\hline Multigravida & $588(57.3)$ & $501(85.2)$ & $87(14.8)$ & & \\
\hline MUAC & $24.77 \pm 3.08$ & $24.52 \pm 2.837$ & $26.47 \pm 4.014$ & 6.93 & $<0.001$ \\
\hline $\mathrm{MUAC}<28 \mathrm{~cm}$ & $852(83)$ & $767(90)$ & $85(10)$ & 34.700 & $<0.001$ \\
\hline$M U A C \geq 28 \mathrm{~cm}$ & $175(17)$ & $129(73.7)$ & $46(26.3)$ & & \\
\hline \multicolumn{6}{|l|}{ Blood pressure } \\
\hline Systolic blood pressure $(\mathrm{mmHg})$ & $112.07 \pm 11.91$ & $111.57 \pm 11.31$ & $115.46 \pm 15.01$ & 3.508 & $<0.001$ \\
\hline Diastolic blood pressure (mmHg) & $71.91 \pm 10.22$ & $71.60 \pm 9.88$ & $74.05 \pm 12.09$ & 2.565 & 0.010 \\
\hline \multicolumn{6}{|l|}{ Blood glucose level $^{b}$} \\
\hline Fasting blood glucose (mg/dL) & $81.17 \pm 12.960$ & $78.3 \pm 9.55$ & $100.81 \pm 15.88$ & 22.779 & $<0.001$ \\
\hline 1-h blood glucose (OGTT) (mg/dl) & $140.69 \pm 24.55$ & $137.31 \pm 22.0$ & $163.82 \pm 28.42$ & 12.368 & $<0.001$ \\
\hline
\end{tabular}


Table 1 Socio demographic and clinical characteristics of the study participants attending antenatal care at Gondar town public health facilities, Northwest Ethiopia: March 2018-January 2019 ( $N=1027)$ (Continued)

\begin{tabular}{|c|c|c|c|c|c|}
\hline \multirow[t]{2}{*}{ Variables } & \multicolumn{3}{|l|}{$\mathrm{n}(\%)$ or mean $\pm \mathrm{SD}$} & \multirow[t]{2}{*}{$t / x^{2}$} & \multirow[t]{2}{*}{$P$ value } \\
\hline & Total participants $(n=1027)$ & Normal $(n=896)$ & $\operatorname{GDM}(n=131)$ & & \\
\hline 2-h blood glucose (OGTT) (mg/dl) & $119.10 \pm 19.75$ & $116.22 \pm 17.40$ & $138.76 \pm 23.40$ & 13.188 & $<0.001$ \\
\hline Hemoglobin $(\mathrm{g} / \mathrm{dl})^{c}$ & $12.609 \pm 1.75$ & $12.64 \pm 1.74$ & $12.39 \pm 1.80$ & -1.545 & 0.123 \\
\hline Normal $(\mathrm{Hb} \geq 11 \mathrm{~g} / \mathrm{dl})$ & $874(86.6)$ & $769(88.0)$ & $105(12.0)$ & 1.949 & 0.163 \\
\hline Anemia $(\mathrm{Hb}<11 \mathrm{~g} / \mathrm{dl})$ & $135(13.4)$ & $113(83.7)$ & $22(16.3)$ & & \\
\hline
\end{tabular}

GDM gestational diabetes mellitus, $h$ hour, $t$ student $\mathrm{t}$ value, $x^{2}$ chi square, $H b$ hemoglobin, $g / d l$ gram per deciliter, $m g / d l$ milligram deciliter, OGTT oral glucose tolerance test, MUAC Mid upper arm circumference

aDivorced or widowed

${ }^{b}$ Blood glucose value at regular time (24-28 weeks)

${ }^{\mathrm{c}} 18$ participants were missed $(N=1009)$

FPG and OGTT were used in the updated diagnostic criteria. On the other hand, the finding is lower than those of studies conducted in Tanzania (19.5\%) [10] and South Africa (25.8\%) [46] which used similar diagnostic criteria. This evidence indicates that the prevalence of GDM might also be affected not only by different diagnostic criteria but also by the characteristics of the population [2, 45, 46]. Increased testing for GDM, change in lifestyle, and the rising prevalence of overweight and obesity might have contributed [47].

Women with the mid-upper arm circumference of $\geq 28 \mathrm{~cm}$ were two times more likely to develop GDM than women with MUAC $<28 \mathrm{~cm}$. This finding agreed with findings from Tanzania by Mwanri et al. [7] and Njete et al [10]. .Although, pre-gestational weight was not available in this study, different studies in Egypt,
Ghana and South Africa which considered obesity using BMI noted its significant association with GDM [14, 15, 48]. Similarly, a review and meta-analysis by Nelson SM et al [49]. revealed that pre-pregnancy BMI was more strongly associated with the risk of GDM. This was happened by the fact that the decreased insulin sensitivity in obese pregnancies, resulted increases the blood glucose level $[49,50]$. Overweight or obesity exposed to sedentary life led to obesity due to inactive lifestyle. This cycle also adversely affects the glucose metabolism. Likewise, we expect a further rise in GDM in the coming years as obesity is emerging as a public health problem.

Pregnant women with a previous history of GDM had six fold more increased odds of developing of the problem during the pregnancy at the moment. This finding was in line with those of studies in Egypt [48], Nigeria

Table 2 Behavioral and life style characteristics of the study participants attending antenatal care at Gondar town public health facilities, Northwest Ethiopia: March 2018-January 2019 ( $N=1027)$

\begin{tabular}{|c|c|c|c|c|c|}
\hline Variables & Total participants $(n=1027)$ & Normal $(n=896)$ & GDM $(n=131)$ & $x^{2}$ & $P$ value \\
\hline \multicolumn{6}{|c|}{ Level of physical activity } \\
\hline High & $322(31.4)$ & $299(92.9)$ & $23(7.1)$ & 100.841 & $<0.001$ \\
\hline Moderate & $460(44.8)$ & $429(93.3)$ & $31(6.7)$ & & \\
\hline Low & $245(23.9)$ & $168(68.6)$ & $77(31.4)$ & & \\
\hline \multicolumn{6}{|c|}{ Dietary diversity status } \\
\hline Adequate $(\geq 5)$ & $497(48.4)$ & $461(92.8)$ & $36(7.2)$ & 26.294 & $<0.001$ \\
\hline Inadequate $(<5)$ & $530(51.6)$ & $435(82.1)$ & $95(17.9)$ & & \\
\hline \multicolumn{6}{|l|}{ Alcohol intake } \\
\hline No & $574(55.9)$ & $497(86.6)$ & $77(13.4)$ & 0.508 & 0.476 \\
\hline Yes & $453(44.1)$ & $339(88.1)$ & $54(11.9)$ & & \\
\hline \multicolumn{6}{|l|}{ Coffee intake } \\
\hline No & $291(28.3)$ & $249(85.6)$ & $42(14.4)$ & 1.027 & 0.311 \\
\hline Yes & $736(71.7)$ & $647(87.9)$ & $89(12.1)$ & & \\
\hline \multicolumn{6}{|l|}{ Antenatal depression } \\
\hline No & $938(91.3)$ & $839(89.4)$ & 99 (10.6) & 47.128 & $<0.001$ \\
\hline Yes & $89(8.7)$ & $57(64)$ & $32(36)$ & & \\
\hline
\end{tabular}


Table 3 Obstetric history of the study participants attending antenatal care at Gondar town public health facilities, Northwest Ethiopia: March 2018-January $2019(N=588)$

\begin{tabular}{|c|c|c|c|c|c|}
\hline Variables & Total participants $(n=588)$ & Normal $(n=502)$ & $\operatorname{GDM}(n=86)$ & $x^{2}$ & $P$ value \\
\hline \multicolumn{6}{|c|}{ History of having macrocosmic baby } \\
\hline No & $517(87.9)$ & $453(87.6)$ & $64(12.4)$ & \multirow[t]{2}{*}{17.309} & \multirow[t]{2}{*}{$<0.001$} \\
\hline Yes & $71(12.1)$ & $49(69)$ & $22(31)$ & & \\
\hline \multicolumn{6}{|c|}{ History of delivery by caesarean delivery } \\
\hline No & $491(83.5)$ & $423(86.2)$ & $68(13.8)$ & \multirow[t]{2}{*}{1.437} & \multirow[t]{2}{*}{0.231} \\
\hline Yes & $97(16.5)$ & $79(81.4)$ & $18(18.6)$ & & \\
\hline \multicolumn{6}{|c|}{ History of abortion } \\
\hline No & $422(71.8)$ & $368(87.2)$ & $54(12.8)$ & \multirow[t]{2}{*}{4.007} & \multirow[t]{2}{*}{0.045} \\
\hline Yes & $166(28.2)$ & $134(80.7)$ & $32(19.3)$ & & \\
\hline \multicolumn{6}{|c|}{ History of still birth } \\
\hline No & $550(93.5)$ & $476(86.5)$ & $74(13.5)$ & \multirow[t]{2}{*}{9.351} & \multirow[t]{2}{*}{0.002} \\
\hline Yes & $38(6.5)$ & $26(68.4)$ & $12(31.6)$ & & \\
\hline \multicolumn{6}{|c|}{ Preterm labor } \\
\hline No & $546(92.9)$ & $469(85.9)$ & $77(14.1)$ & \multirow[t]{2}{*}{1.676} & \multirow[t]{2}{*}{0.195} \\
\hline Yes & $42(7.1)$ & $33(78.6)$ & $9(21.4)$ & & \\
\hline \multicolumn{6}{|c|}{ Previous history GDM } \\
\hline No & $534(90.8)$ & $477(89.3)$ & $57(10.7)$ & \multirow[t]{2}{*}{72.718} & \multirow[t]{2}{*}{$<0.001$} \\
\hline Yes & $54(9.2)$ & 25 (46.3) & $29(53.7)$ & & \\
\hline
\end{tabular}

GDM Gestational Diabetes Mellitus, $x^{2}$ chi square

[51], Colorado [52], and a systematic review by Catherine Kim et al. [53]. The frequent occurrence of GDM showed the presence of communal risk factors in succeeding pregnancies [54]. Similarly, GDM was four fold higher in women with family history of diabetes. The finding was consistent with an evidence in the US [55] and studies in
Iran $[56,57]$. This might be the fact that the hyperglycemia was linked with a genetically dysfunction of beta cell and familial predisposition to insulin secretory defects [58]. Moreover, living standards and lifestyles of families are more likely similar resulting in sharing the related risk factors [59].



Fig. 1 Analysis of the abnormal blood glucose reading among pregnant women with GDM attending antenatal care at Gondar town public health facilities, Northwest Ethiopia: March 2018-January $2019(N=131)$ 
Table 4 Factors associated with GDM among pregnant women attending antenatal care at Gondar town public health facilities, Northwest Ethiopia: March 2018-January 2019

\begin{tabular}{|c|c|c|c|c|c|c|}
\hline Variables & $\begin{array}{l}\text { Non-GDM } \\
\mathrm{n}(\%)\end{array}$ & $\begin{array}{l}\text { GDM } \\
\mathrm{n}(\%)\end{array}$ & $\operatorname{COR}(95 \% \mathrm{Cl})$ & $P$-value & $\operatorname{AOR}(95 \% \mathrm{Cl})^{\mathrm{a}}$ & $P$ value \\
\hline \multicolumn{7}{|l|}{ Maternal age (years) } \\
\hline$<25$ & $304(94.1)$ & $19(5.8)$ & 1 & & 1 & \\
\hline $25-29$ & $335(91.4)$ & $31(8.5)$ & $1.48(0.82,2.68)$ & 0.194 & $0.99(0.32,3.12)$ & 0.994 \\
\hline $30-34$ & $168(78.5)$ & $46(21.5)$ & $4.38(2.49,7.72)$ & $<0.001$ & $2.24(0.73,6.83)$ & 0.156 \\
\hline$\geq 35$ & $89(71.8)$ & $35(28.2)$ & $6.29(3.43,11.54)$ & $<0.001$ & $3.05(0.88,10.51)$ & 0.077 \\
\hline \multicolumn{7}{|l|}{ Marital status } \\
\hline Married & $831(87.9)$ & $114(12.1)$ & 1 & & 1 & \\
\hline Single and others ${ }^{b}$ & 65(79.3) & $17(20.7)$ & $1.91(1.08,3.37)$ & 0.026 & $2.04(0.72,5.78)$ & 0.179 \\
\hline \multicolumn{7}{|l|}{ Educational level } \\
\hline Not formal education & $168(84)$ & $32(16.0)$ & 1 & & 1 & \\
\hline Primary education & $194(84.7)$ & $35(15.3)$ & $0.95(0.56,1.60)$ & 0.838 & $1.82(0.75,4.43)$ & 0.184 \\
\hline Secondary education and above & $534(89.3)$ & $64(10.7)$ & $0.63(0.40, .99)$ & 0.048 & $0.90(0.39,2.11)$ & 0.815 \\
\hline \multicolumn{7}{|l|}{ Employment status } \\
\hline Unemployed & $556(89.5)$ & $65(10.5)$ & 1 & & 1 & \\
\hline Employed & $340(83.7)$ & $66(16.3)$ & $1.66(1.15,2.40)$ & 0.007 & $1.44(0.71,2.91)$ & 0.309 \\
\hline \multicolumn{7}{|l|}{ MUAC } \\
\hline$M U A C<28 \mathrm{~cm}$ & $767(90)$ & $85(10)$ & 1 & & 1 & \\
\hline$M U A C \geq 28 \mathrm{~cm}$ & $129(73.7)$ & $46(26.3)$ & $3.22(2.15,4.82)$ & $<0.001$ & $2.25(1.18,4.26)$ & 0.013 \\
\hline SBP $(\mathrm{mmHg})$ & $111.57 \pm 11.31$ & $115.46 \pm 15.01$ & $1.025(1.01,1.04)$ & 0.001 & $1.024(0.99,1.06)$ & 0.132 \\
\hline $\mathrm{DBP}(\mathrm{mmHg})$ & $71.60+9.882$ & $74.05 \pm 12.09$ & $1.022(1.01,1.04)$ & 0.011 & $0.99(0.96,1.03)$ & 0.757 \\
\hline \multicolumn{7}{|l|}{ Anemic status } \\
\hline Normal $(\mathrm{Hb} \geq 11 \mathrm{~g} / \mathrm{dl})$ & $769(88.0)$ & $105(12.0)$ & 1 & & 1 & \\
\hline Anemia $(\mathrm{Hb}<11 \mathrm{~g} / \mathrm{dl})$ & $113(83.7)$ & $22(16.3)$ & $1.43(0.86,2.35)$ & 0.164 & $1.73(0.81,3.70)$ & 0.160 \\
\hline \multicolumn{7}{|l|}{ Level of physical activity } \\
\hline High & $299(92.9)$ & $23(7.1)$ & 1 & & 1 & \\
\hline Moderate & $429(93.3)$ & $31(6.7)$ & $0.94(.054,1.64)$ & 0.827 & $0.613(0.27,1.38)$ & 0.238 \\
\hline Low & $168(68.6)$ & 77 (31.4) & $5.96(3.60,9.85)$ & $<0.001$ & $3.36(1.60,7.04)$ & 0.001 \\
\hline \multicolumn{7}{|l|}{ Dietary diversity status } \\
\hline Adequate $(\geq 5)$ & $461(92.8)$ & $36(7.2)$ & 1 & & 1 & \\
\hline Inadequate $(<5)$ & $435(82.1)$ & $95(17.9)$ & $2.80(1.86,4.19)$ & $<0.001$ & $1.90(1.02,3.53)$ & 0.042 \\
\hline \multicolumn{7}{|l|}{ Family history of diabetes } \\
\hline No & $862(89.3)$ & $103(10.7)$ & 1 & & 1 & \\
\hline Yes & $34(54.8)$ & $28(45.2)$ & $6.89(4.02,11.83)$ & $<0.001$ & $4.03(1.57,10.35)$ & 0.004 \\
\hline \multicolumn{7}{|l|}{ Parity } \\
\hline Nullipara & $449(89.1)$ & $55(10.9)$ & 1 & & 1 & \\
\hline Primipara & $243(87.7)$ & $34(12.3)$ & $1.14(0.72,1.80)$ & 0.567 & $0.77(0.28,2.16)$ & 0.626 \\
\hline Multipara & $204(82.9)$ & $42(17.1)$ & $1.68(1.09,2.60)$ & 0.019 & $0.99(0.34,2.81)$ & 0.987 \\
\hline \multicolumn{7}{|l|}{ History of macrocosmic baby } \\
\hline No & $453(87.6)$ & $64(12.4)$ & 1 & 1 & 1 & \\
\hline Yes & $49(69)$ & $22(31)$ & $3.18(1.80,5.60)$ & $<0.001$ & $1.54(0.70,3.37)$ & 0.283 \\
\hline \multicolumn{7}{|l|}{ History of abortion } \\
\hline No & $368(87.2)$ & $54(12.8)$ & 1 & & 1 & \\
\hline Yes & $134(80.7)$ & $32(19.3)$ & $1.63(1.01,2.63)$ & 0.047 & $1.014(0.51,2.03)$ & 0.968 \\
\hline
\end{tabular}


Table 4 Factors associated with GDM among pregnant women attending antenatal care at Gondar town public health facilities, Northwest Ethiopia: March 2018-January 2019 (Continued)

\begin{tabular}{|c|c|c|c|c|c|c|}
\hline Variables & $\begin{array}{l}\text { Non-GDM } \\
\mathrm{n}(\%)\end{array}$ & $\begin{array}{l}\text { GDM } \\
\text { n (\%) }\end{array}$ & COR $(95 \% \mathrm{Cl})$ & $P$-value & $\operatorname{AOR}(95 \% \mathrm{Cl})^{a}$ & $P$ value \\
\hline \multicolumn{7}{|c|}{ History of still birth } \\
\hline No & $476(86.5)$ & 74 (13.5) & 1 & & 1 & \\
\hline Yes & $26(68.4)$ & 12 (31.6) & $2.97(1.44,6.14)$ & 0.003 & $1.42(0.48,4.15)$ & 0.526 \\
\hline \multicolumn{7}{|c|}{ Previous GDM } \\
\hline No & 477 (89.3) & $57(10.7)$ & 1 & & 1 & \\
\hline Yes & $25(46.3)$ & $29(53.7)$ & $9.71(5.32,17.71)$ & $<0.001$ & $5.82(2.57,13.18)$ & $<0.001$ \\
\hline \multicolumn{7}{|c|}{ Antenatal depression } \\
\hline No & $839(89.4)$ & 99 (10.6) & 1 & & 1 & \\
\hline Yes & $57(64)$ & $32(36)$ & $4.76(2.94,7.69)$ & $<0.001$ & $4.12(1.85,9.20)$ & 0.001 \\
\hline
\end{tabular}

OR odds ratio, $C$ confidence interval, MUAC mid-upper arm circumference, SBP systolic blood pressure, DBP diastolic blood pressure, 1 Reference

${ }^{a}$ Adjusted for factors including maternal age, marital status, educational level, employment status, MUAC, systolic blood pressure, diastolic blood pressure, anemia, level of physical activity, dietary diversity status, family history of diabetes, parity, history of macrocosmic baby, history of abortion, history of still birth, previous GDM and antenatal depression

${ }^{b}$ Divorced or widowed

Low physical activity increases the likelihood of developing GDM at least three times compared to a high level of physical activity during pregnancy. This finding was in line with a study conducted in Vietnam [60], a metaanalysis by Tobias et al. [61], and review by Biase et al. [59]. Increased level of physical activity during pregnancy reduces glucose levels by preventing weight gain and enhancement of insulin sensitivity [13, 60, 62].

Pregnant women with inadequate dietary diversity had two times higher GDM than their counterparts. Healthy eating habits and the consumption of food from a variety of dietary groups during pregnancy contributes to the prevention of pregnancy-related complications [63]. Despite a piece of contradict evidence regarding the impact of dietary variability during pregnancy and developing GDM, studies revealed the association between dietary diversity and GDM [17, 64-66]. The possible reason for the association between inadequate dietary diversity and GDM might be the fact that the majority of women with GDM were classified as inadequate dietary diversity group. Similarly, a large proportion women relied on the monotonous food group in which cereals were the most common consumed food group. Their diets were likely to have been excessive in refined carbohydrates and sugars. On the other hand, dietary diversity varied across a range of factors related to the demographic and socioeconomic status of individuals and households. Further research is required to know whether improving dietary pattern adherence during pregnancy is associated with a lower risk of GDM. Our result suggests that clinical and public health efforts to encourage dietary diversity for women of reproductive age might yield benefits in the reduction of GDM in future pregnancies.
Women with antenatal depression had four times higher GDM compared to women with non-depressive symptoms. The finding is supported studies by Morrison et al. [67] showed antenatal depression as a risk factor for GDM. The finding was in line with that of a study in Chicago which showed that a history of prenatal depression increased the risk for the development of GDM [68]. The association between depression and GDM was bidirectional [69] and could be explained by shared psychosocial and physiological factors for these comorbid situations. Pregnant women who had depression were more likely to practice unhealthy behaviors like sedentary lifestyle which lead to the risk of developing GDM [70]. Moreover, change in cortisol levels by depression have hyperglycemic effects [71, 72].

This study has strengths and limitation. The strength of the study was that it employed recent and universal screening tool to detect GDM and it has been done for all pregnant women at 24-28 weeks gestation. They underwent a two-hour $75 \mathrm{~g}$ OGTT, and updated standard reference cutoff values were considered. Besides, for pregnant women who had risk factors for GDM and whose OGTT results were negative at the regular test were tested again at late gestational age. WHO recommends that in settings where laboratories or proper storages and transport of blood samples is not guaranteed, which is the case in resource limited countries like Ethiopia, the use of point of care tests may influence the result [23]. However, we used plasma-calibrated hand-held glucometers because of convenience and acceptable reliability. Moreover, due to the nature of study design which restricted causal inference and could not reveal the temporal sequence between the 
factors and the outcome variable which could be limitation of the study.

\section{Conclusions}

In conclusion, the overall prevalence of GDM was found to be high and a major public health concern among pregnant women in Gondar town, Northwest Ethiopia. Previous history of GDM, antenatal depression, family history of diabetes, low physical activity, overweight and/or obese women and inadequate dietary diversity were significantly associated with GDM. Given the imminent burden of obesity, unhealthy eating, and physical inactivity, a substantial threat of GDM is anticipated in Ethiopia. This may be an appropriate time to think about considering the need for routine screening of GDM to reduce the impact of the diseases in the country. In this regard, our study may serve as a baseline for larger studies and background evidence for policy debates for universal GDM screening in the existing health care system. Integrating healthy lifestyle choices into ANC services, such as reduced obesity, healthy eating, improvement in physical activities and effective strategies for coping with depression are strongly recommended.

\section{Supplementary information}

Supplementary information accompanies this paper at https://doi.org/10. 1186/s12884-019-2492-3.

Additional file 1. English version consent form and questionnaire for GDM survey among women attending ANC at Gondar town public health facilities, Northwest Ethiopia.

Additional file 2. The specifications of the HemoCue Glucose B-201+ glucometer.

\section{Abbreviations}

ANC: Antenatal care; AOR: Adjusted odds ratio; BMI: Body mass index; BP: Blood pressure; Cl: Confidence interval; CM: Centi meter; DBP: Diastolic blood pressure; DM: Diabetes mellitus; EDPS: Edinburgh Postnatal Depression Scale; FANTA: Food and Nutrition Technical Assistance; FPG: Fasting plasma glucose; GDM: Gestational diabetes mellitus; HAPO: Hyperglycemia and adverse pregnancy outcome; IADPSG: International Association of the Diabetes and Pregnancy Study Group; IDF: International diabetes federation; IGT: Impaired glucose tolerance; IPAQ: International Physical Activity Questionnaire; LMIC: Low and middle-income countries; LNMP: Last normal menstrual period; MDDS: Minimum dietary diversity score; MET: Metabolic equivalent of task; MUAC: Mid-upper arm circumference; NCD: Noncommunicable diseases; OGTT: Oral glucose tolerance test; OR: Odds ratio; SBP: Systolic blood pressure; SD: Standard deviation; SPSS: Statistical package for social sciences; WHO: World Health Organization

\section{Acknowledgements}

We would also like to forward our sincere gratitude to the African Union Commission (AU) for funding this study, the Pan African University Life and Earth Science Institute (PAULESI), and University of Ibadan (UI) for hosting the program and University of Gondar. We would also like to acknowledge the Setema Limited PLC for their material support (Hemocue Glucose 201 with micro cuvette). We appreciate Dr. Mulat Adefris (Associate professor of Obstetrics and Gynecology) at the University of Gondar for his professional assistant and Mr. Demeke Dessu of the University of Gondar for his editing assistance. Last but not least, we would like to extend our thanks to all data collectors and study participants who participated in the study.

\section{Authors' contributions}

AAM conceived and designed the study, analyzed the data and prepared the manuscript. OO \& YKG assisted the development of the research idea, the analysis, interpretation and preparation of the manuscript. All authors read and approved the final manuscript.

\section{Funding}

This study was sponsored by the Pan African University (PAU), a continental initiative of the African Union Commission (AU), Addis Ababa, Ethiopia, as part of the Ph.D. Fellowship Program in Reproductive Health Sciences. The funder had no any role in design of the study, data collection, analysis, interpretation of the data and preparation of the manuscript.

\section{Availability of data and materials}

The datasets used and/or analyzed during the current study are available from the corresponding author on reasonable request.

\section{Ethics approval and consent to participate}

The study was conducted after ethical approval was obtained from the Institutional Review Board (IRB) of the University of Ibadan/University College Hospital (Ref.No; UI/EC/17/0435) and the IRB of the University of Gondar (Ref.No; ON/P/RCS/05/811/2018). Permission from the Amhara Public Health Institute and the health authorities of the study sites was also received prior to the start of the study. Before enrolment, participants were informed about the study, its aims, effects, and importance of screening. Written consent was obtained by trained data collectors. Then, participants were subjected to full history taking through clinical examinations and laboratory investigations. All information was made anonymous in order to maintain confidentiality. Participants diagnosed with GDM was referred to health providers and get possible treatment options in their respective public health facilities.

Consent for publication

Not applicable.

\section{Competing interests}

The authors declare that they have no competing interests.

\section{Author details}

${ }^{1}$ Pan African University Life and Earth Sciences Institute (including health and agriculture), Department of Obstetrics and Gynaecology, College of Medicine, University of Ibadan, Ibadan, Nigeria. ${ }^{2}$ Department of Epidemiology and Biostatistics, Institute of Public Health, University of Gondar, Gondar, Ethiopia. ${ }^{3}$ Department of Obstetrics and Gynaecology, College of Medicine, University College Hospital, University of Ibadan, Ibadan, Nigeria.

Received: 27 March 2019 Accepted: 5 September 2019

Published online: 13 September 2019

\section{References}

1. World Health Organization (WHO). Diagnostic criteria and classification of hyperglycaemia first detected in pregnancy. 2013. Retrived from: http:// apps.who.int/iris/bitstream/10665/85975/1/WHO_NMH_MND_13.2_eng.pdf. On 24 Feb 2019

2. Hartling L, Dryden DM, Guthrie A, Muise M, Vandermeer B, Aktary WM, et al. Screening and diagnosing gestational diabetes mellitus. Evidence report/ technology assessment. 2012;210:1-327.

3. Metzger BE, Buchanan TA, Coustan DR, De Leiva A, Dunger DB, Hadden DR, et al. Summary and recommendations of the fifth international workshopconference on gestational diabetes mellitus. Diabetes Care. 2007; 30(Supplement 2:S251-S60.

4. Ogurtsova K, da Rocha Fernandes J, Huang Y, Linnenkamp U, Guariguata L, Cho N, et al. IDF diabetes atlas: global estimates for the prevalence of diabetes for 2015 and 2040. Diabetes Res Clin Pract. 2017;128:40-50.

5. Mwanri AW, Kinabo J, Ramaiya K, Feskens EJ. Gestational diabetes mellitus in sub-Saharan Africa: systematic review and metaregression on prevalence and risk factors. Tropical Med Int Health. 2015;20(8):983-1002.

6. Zhu Y, Zhang C. Prevalence of gestational diabetes and risk of progression to type 2 diabetes: a global perspective. Curr Diab Rep. 2016;16(1):7.

7. Mwanri AW, Kinabo J, Ramaiya K, Feskens EJ. Prevalence of gestational diabetes mellitus in urban and rural Tanzania. Diabetes Res Clin Pract. 2014; 103(1):71-8 
8. Kuti MA, Abbiyesuku FM, Akinlade KS, Akinosun OM, Adedapo KS, Adeleye $\mathrm{JO}$, et al. Oral glucose tolerance testing outcomes among women at high risk for gestational diabetes mellitus. Journal of clinical pathology. 2011. https://doi.org/10.1136/jcp.2010.087098.

9. Niyibizi JB, Safari F, Ahishakiye JB, Habimana JB, Mapira H, Mutuku NC. Gestational diabetes mellitus and its associated risk factors in pregnant women at selected health facilities in Kigali city, Rwanda. J Diabetes Mellitus. 2016;6(04):269.

10. Njete H, John B, Mlay P, Mahande M, Msuya S. Prevalence, predictors and challenges of gestational diabetes mellitus screening among pregnant women in northern Tanzania. Tropical Med Int Health. 2018;23(2):236-42.

11. Seyoum B, Kiros K, Haileselase T, Leole A. Prevalence of gestational diabetes mellitus in rural pregnant mothers in northern Ethiopia. Diabetes Res Clin Pract. 1999;46(3):247-51.

12. Management Sciences for Health; Gestational Diabetes: A Risk Factor for Maternal Death in Tigray, Ethiopia, 5 March 2015. https://www.msh.org/ sites/msh.org/files/eth_enhat_techbrief10_webv.pdf. On 18 Nov 2018.

13. van Poppel MN, Oostdam N, Eekhoff ME, Wouters MG, van Mechelen W, Catalano PM. Longitudinal relationship of physical activity with insulin sensitivity in overweight and obese pregnant women. J Clin Endocrinol Metab. 2013;98(7):2929-35.

14. Macaulay S, Ngobeni M, Dunger DB, Norris SA. The prevalence of gestational diabetes mellitus amongst black south African women is a public health concern. Diabetes Res Clin Pract. 2018;139:278-87.

15. Oppong SA, Ntumy MY, Amoakoh-Coleman M, Ogum-Alangea D, ModeyAmoah E. Gestational diabetes mellitus among women attending prenatal care at Korle-Bu teaching hospital, Accra, Ghana. Int J Gynecol Obstet. 2015; 131(3):246-50

16. Liang C, DeCourcy K, Prater MR. High-saturated-fat diet induces gestational diabetes and placental vasculopathy in C57BL/6 mice. Metabolism. 2010; 59(7):943-50.

17. Bo S, Menato G, Lezo A, Signorile A, Bardelli C, De Michieli F, et al. Dietary fat and gestational hyperglycaemia. Diabetologia. 2001;44(8):972-8.

18. Moses RG, Shand JL, Tapsell LC. The recurrence of gestational diabetes: could dietary differences in fat intake be an explanation? Diabetes Care. 1997;20(11):1647-50

19. Catalano PM, Tyzbir ED, Roman NM, Amini SB, Sims EA. Longitudinal changes in insulin release and insulin resistance in nonobese pregnant women. Am J Obstet Gynecol. 1991;165(6 Pt 1):1667-72.

20. Plows JF, Stanley JL, Baker PN, Reynolds CM, Vickers MH. The pathophysiology of gestational diabetes mellitus. Int J Mol Sci. 2018;19(11): 3342.

21. Farrar D, Duley L, Dowswell T, Lawlor DA. Different strategies for diagnosing gestational diabetes to improve maternal and infant health. Cochrane Database Syst Rev. 2017;8:CD007122.

22. International Diabetes Federation (IDF). GDM model of care implementation protocol guidelines for healthcare professionals. 2015. Retrieved from https://www.idf.org/.../guidelines/77-idf-gdm-model-of-care-implementationprotocol.pdf. On 27 Nov 2018.

23. Hod M, Kapur A, Sacks DA, Hadar E, Agarwal M, Di Renzo GC, et al. The International Federation of Gynecology and Obstetrics (FIGO) initiative on gestational diabetes mellitus: a pragmatic guide for diagnosis, management, and care. Int J Gynecol Obstet. 2015;131:S173-211.

24. Buchanan TA, Xiang AH, Page KA. Gestational diabetes mellitus: risks and management during and after pregnancy. Nat Rev Endocrinol. 2012:8(11): 639-49

25. Federal Democratic Republic of Ethiopia Central Statistical Agency Population Projection of Ethiopia for All Regions At Wereda Level from 2014-2017. Addis Ababa: Central Statistical Agency; 2014.

26. Pylvanen V, Pakarinen A, Knip M, Isojarvi J. Insulin-related metabolic changes during treatment with valproate in patients with epilepsy. Epilepsy Behav. 2006;8(3):643-8.

27. Kwon S, Hermayer KL, Hermayer K. Glucocorticoid-induced hyperglycemia. Am J Med Sci. 2013;345(4):274-7.

28. American Diabetes Association. Classification and diagnosis of diabetes. Sec. 2. In standards ofMedical Care in Diabetesd 2017. Diabetes Care. 2017 40(Suppl. 1):S11-24.

29. Colagiuri S, Falavigna M, Agarwal MM, Boulvain M, Coetzee E, Hod M, et al. Strategies for implementing the WHO diagnostic criteria and classification of hyperglycaemia first detected in pregnancy. Diabetes Res Clin Pract. 2014;103(3):364-72.
30. Hagströmer M, Oja P, Sjöström M. The international physical activity questionnaire (IPAQ): a study of concurrent and construct validity. Public Health Nutr. 2006;9(6):755-62.

31. Food and Agriculture Organization (FAO). Minimum dietary diversity for women: a guide for measurement, food and agriculture organization of the United Nations, USAID's food and nutrition technical assistance III project (FANTA), managed by FHI 360, Rome. 2016. Retrieved from www.fao.org/3/ a-i5486e.pdf. On 12 Dec 2018.

32. Gale CR, Javaid MK, Robinson SM, Law CM, Godfrey KM, Cooper C. Maternal size in pregnancy and body composition in children. J Clin Endocrinol Metab. 2007;92(10):3904-11.

33. Ricalde AE, Velásquez-Meléndez G, Tanaka ACA, de Siqueira AA. Mid-upper arm circumference in pregnant women and its relation to birth weight. Rev Saude Publica. 1998;32:112-7.

34. Oza-Frank R, Ali MK, Vaccarino V, Narayan KV. Asian Americans: diabetes prevalence across US and World Health Organization weight classifications. Diabetes Care. 2009:32(9):1644-6.

35. Murray D, Cox JL. Screening for depression during pregnancy with the Edinburgh Depression Scale (EDDS). J Reprod Infant Psychol. 1990:8(2):99-107.

36. Tesfaye M, Hanlon C, Wondimagegn D, Alem A. Detecting postnatal common mental disorders in Addis Ababa, Ethiopia: validation of the Edinburgh postnatal depression scale and Kessler scales. J Affect Disord. 2010;122(1-2):102-8

37. Wado YD, Afework MF, Hindin MJ. Effects of maternal pregnancy intention, depressive symptoms and social support on risk of low birth weight: a prospective study from southwestern Ethiopia. PLoS One. 2014;9(5):e96304.

38. Biratu A, Haile D. Prevalence of antenatal depression and associated factors among pregnant women in Addis Ababa, Ethiopia: a cross-sectional study. Reprod Health. 2015;12(1):99.

39. Golbasi Z, Kelleci M, Kisacik G, Cetin A. Prevalence and correlates of depression in pregnancy among Turkish women. Matern Child Health J. 2010;14(4):485-91.

40. D'Orazio P, Burnett RW, Fogh-Andersen N, Jacobs E, Kuwa K, Külpmann WR, et al. Approved IFCC recommendation on reporting results for blood glucose (abbreviated). Clin Chem. 2005;51(9):1573-6.

41. World Health Organization (WHO). Diagnostic criteria and classification of hyperglycaemia first detected in pregnancy. 2013. Available from: http:// apps.who.int/iris/bitstream/10665/8597/1/WHO_NMH_MND_13.2_eng.pdf.

42. Diabetes IAo, Panel PSGC. International association of diabetes and pregnancy study groups recommendations on the diagnosis and classification of hyperglycemia in pregnancy. Diabetes Care. 2010;33(3):676-82.

43. World Health Organization (WHO). Haemoglobin concentrations for the diagnosis of anaemia and assessment of severity. 2011. Retrieved from https://www.who.int/vmnis/indicators/haemoglobin/en/. On 12 Dec 2018.

44. Khalil NA, Fathy WM, Mahmoud NS. Screening for gestational diabetes among pregnant women attending a rural family health center-Menoufia governorate-Egypt. J Fam Med Health Care. 2017;3(1):6-11.

45. Olagbuji BN, Atiba AS, Olofinbiyi BA, Akintayo AA, Awoleke JO, Ade-Ojo IP, et al. Prevalence of and risk factors for gestational diabetes using 1999, 2013 WHO and IADPSG criteria upon implementation of a universal one-step screening and diagnostic strategy in a sub-Saharan African population. Eur J Obstet Gynecol Reprod Biol. 2015;189:27-32.

46. Adams S, Rheeder P. Screening for gestational diabetes mellitus in a south African population: prevalence, comparison of diagnostic criteria and the role of risk factors. S Afr Med J. 2017;107(6):523-7.

47. Organization WH. Global report on diabetes: World Health Organization; 2016. 2017.

48. El Sagheer GM, Hamdi L. Prevalence and risk factors for gestational diabetes mellitus according to the diabetes in pregnancy study group India in comparison to International Association of the diabetes and pregnancy study groups in El-Minya, Egypt. Egypt J Intern Med. 2018;30(3):131.

49. Nelson SM, Matthews P, Poston L. Maternal metabolism and obesity: modifiable determinants of pregnancy outcome. Hum Reprod Update. 2010;16(3):255-75.

50. Huda SS, Brodie LE, Sattar N. Obesity in pregnancy: prevalence and metabolic consequences. Elsevier; Seminars in Fetal and Neonatal Medicine. 2010;15(2):70-6.

51. Ogonowski J, Miazgowski T, Engel K, Celewicz Z. Birth weight predicts the risk of gestational diabetes mellitus and pregravid obesity. Nutrition (Burbank, Los Angeles County, Calif). 2014;30(1):39-43.

52. Dabelea D, Snell-Bergeon JK, Hartsfield CL, Bischoff KJ, Hamman RF, McDuffie RS. Increasing prevalence of gestational diabetes mellitus (GDM) 
over time and by birth cohort: Kaiser Permanente of Colorado GDM screening program. Diabetes Care. 2005;28(3):579-84.

53. Kim C, Berger DK, Chamany S. Recurrence of gestational diabetes mellitus: a systematic review. Diabetes care. 2007;30(5):1314-9.

54. Spong C, Guillermo L, Kuboshige J, Cabalum T. Recurrence of gestational diabetes mellitus: identification of risk factors. Am J Perinatol. 1998;15(01): 29-33.

55. Carr DB, Utzschneider KM, Hull RL, Tong J, Wallace TM, Kodama K, et al. Gestational diabetes mellitus increases the risk of cardiovascular disease in women with a family history of type 2 diabetes. Diabetes Care. 2006;29(9): 2078-83.

56. Keshavarz M, Cheung NW, Babaee GR, Moghadam HK, Ajami ME, Shariati M. Gestational diabetes in Iran: incidence, risk factors and pregnancy outcomes. Diabetes Res Clin Pract. 2005;69(3):279-86.

57. Garshasbi A, Faghihzadeh S, Naghizadeh MM, Ghavam M. Prevalence and risk factors for gestational diabetes mellitus in Tehran. J Family Reprod Health. 2008:2(2):75-80.

58. Ehrmann DA, Sturis J, Byrne MM, Karrison T, Rosenfield RL, Polonsky KS. Insulin secretory defects in polycystic ovary syndrome. Relationship to insulin sensitivity and family history of non-insulin-dependent diabetes mellitus. J Clin Invest. 1995;96(1):520-7.

59. Ferrannini E, Gastaldelli A, lozzo P. Pathophysiology of prediabetes. Med Clin. 2011;95(2):327-39

60. Nguyen CL, Pham NM, Lee AH, Nguyen PTH, Chu TK, Ha AW, et al. Physical activity during pregnancy is associated with a lower prevalence of gestational diabetes mellitus in Vietnam. Acta Diabetol. 2018;55(9):955-62.

61. Tobias DK, Zhang C, Van Dam RM, Bowers K, Hu FB. Physical activity before and during pregnancy and risk of gestational diabetes mellitus: a metaanalysis. Diabetes Care. 2011;34(1):223-9.

62. Anjana RM, Sudha V, Lakshmipriya N, Anitha C, Unnikrishnan R, Bhavadharini $B$, et al. Physical activity patterns and gestational diabetes outcomes-the wings project. Diabetes Res Clin Pract. 2016;116:253-62.

63. Cuco G, Fernandez-Ballart J, Sala J, Viladrich C, Iranzo R, Vila J, et al. Dietary patterns and associated lifestyles in preconception, pregnancy and postpartum. Eur J Clin Nutr. 2006;60(3):364.

64. Rifas-Shiman SL, Rich-Edwards JW, Kleinman KP, Oken E, Gillman MW. Dietary quality during pregnancy varies by maternal characteristics in project viva: a US cohort. J Am Diet Assoc. 2009;109(6):1004-11.

65. Saldana TM, Siega-Riz AM, Adair LS. Effect of macronutrient intake on the development of glucose intolerance during pregnancy. Am J Clin Nutr. 2004;79(3):479-86.

66. Wang Y, Storlien LH, Jenkins AB, Tapsell LC, Jin Y, Pan JF, et al. Dietary variables and glucose tolerance in pregnancy. Diabetes Care. 2000;23(4): 460-4.

67. Morrison C, McCook JG, Bailey BA. First trimester depression scores predict development of gestational diabetes mellitus in pregnant rural Appalachian women. J Psychosom Obstet Gynecol. 2016;37(1):21-5.

68. Byrn M, Penckofer S. The relationship between gestational diabetes and antenatal depression. J Obstet Gynecol Neonatal Nurs. 2015;44(2):246-55.

69. Hinkle SN, Buck Louis GM, Rawal S, Zhu Y, Albert PS, Zhang C. A longitudinal study of depression and gestational diabetes in pregnancy and the postpartum period. Diabetologia. 2016;59(12):2594-602.

70. Byrn MA, Penckofer S. Antenatal depression and gestational diabetes. Nurs Womens Health. 2013;17(1):22-33.

71. Lustman PJ, Clouse RE. Depression in diabetic patients: the relationship between mood and glycemic control. J Diabetes Complicat. 2005;19(2):113-22.

72. Silva $\mathrm{N}$, Atlantis $\mathrm{E}$, Ismail K. A review of the association between depression and insulin resistance: pitfalls of secondary analyses or a promising new approach to prevention of type 2 diabetes? Curr Psychiatry Rep. 2012;14(1): 8-14.

\section{Publisher's Note}

Springer Nature remains neutral with regard to jurisdictional claims in published maps and institutional affiliations.

\section{Ready to submit your research? Choose BMC and benefit from:}

- fast, convenient online submission

- thorough peer review by experienced researchers in your field

- rapid publication on acceptance

- support for research data, including large and complex data types

- gold Open Access which fosters wider collaboration and increased citations

- maximum visibility for your research: over $100 \mathrm{M}$ website views per year

At $\mathrm{BMC}$, research is always in progress.

Learn more biomedcentral.com/submissions 